\title{
ROTEIROS DE OBSERVAÇÃO: \\ UMA PROPOSTA DIDÁTICO-PEDAGÓGICA PARA A FORMAÇÃO DE GESTORES EDUCACIONAIS NO CURSO DE PEDAGOGIA.
}

Silvina Julia Fernández ${ }^{\mathrm{i}}$

\begin{abstract}
Resumo: Neste artigo procuro apresentar a proposta didático-pedagógica da disciplina Prática em Política e Administração Educacional e, ao narrá-la, refletir e problematizar sobre seus supostos, intencionalidades, acertos e dificuldades, nas condições institucionais e curriculares do curso de Pedagogia da Universidade Federal do Rio de Janeiro, frente aos desafios que enfrenta a gestão educacional atual. Para isso, num primeiro momento, busco contextualizar a minha ação docente não apenas nesses desafios, mas procuro entender como as demandas por eles gerados se inserem numa perspectiva histórica. A seguir, no meu papel de docente, descrevo narrativamente a situação e os desdobramentos da proposta dessa disciplina, buscando tensioná-la em função autoavaliativa e prospectiva.
\end{abstract}

Palavras-chave: Pedagogia; Formação de gestores; Estágio supervisionado.

\section{GUÍAS DE OBSERVACIÓN: \\ UNA PROPUESTA DIDÁCTICO-PEDAGÓGICA PARA LA FORMACIÓN DE GESTORES EDUCATIVOS EN LA CARRERA DE PEDAGOGIA.}

Resumen: En este artículo busco exponer la propuesta didáctico-pedagógica de la disciplina Práctica en Política y Administración Educacional y, al narrarla, reflexionar y problematizar sobre sus supuestos, intencionalidades, aciertos y dificultades, en las condiciones institucionales y curriculares de la carrera de Pedagogía de la Universidad Federal do Rio de Janeiro, frente a los desafíos que enfrenta la gestión educativa actual. Para ello, en un primer momento, busco contextualizar mi acción docente no sólo en relación a esos desafíos, sino también buscando entender cómo las demandas por ellos generados se plantean en una perspectiva histórica. En seguida, en mi papel de docente, describo narrativamente la situación y los desarrollos de la propuesta de esta disciplina, buscando tensionarla en función autoevaluativa y prospectiva.

Palabras clave: Pedagogía; Formación de gestores; Pasantía.

\section{Introdução}

Há questões que retornam e controvérsias que parecem persistir no debate educacional brasileiro, ainda que as pesquisas e discussões acadêmicas talvez não lhes ofereçam um destaque equipotente. Uma dessas questões refere-se à formação do gestor educacional.

Com efeito, no Brasil, a história da Pedagogia está ligada a essa discussão e, atualmente, a temática voltou a fazer parte da agenda pública educacional, afetando as 
discussões a respeito do currículo do curso de Pedagogia. Que pedagogo temos de formar hoje? Qual o papel da formação específica em Administração/Gestão Escolar/Educacional nessa formação? Que propostas didático-pedagógicas seriam não apenas mais pertinentes, mas também viáveis, na universidade pública brasileira atual?

Como professora da disciplina Prática em Política e Administração Educacional da Universidade Federal do Rio de Janeiro (UFRJ), faço-me persistentemente essas perguntas e, no meio a esses questionamentos, venho propondo diversas tentativas de concretização dessa formação. Contudo, uma dessas propostas vem me parecendo a mais propícia até o momento para essa disciplina, nas condições institucionais e curriculares em que nos encontramos na Faculdade de Educação da UFRJ. Neste artigo, portanto, através da metodologia de relato de experiência, pretendo não apenas apresentar essa proposta, mas também, ao narrá-la, refletir e problematizar sobre seus supostos, intencionalidades, acertos e dificuldades para poder não apenas "fazer memória", e assim registrá-la, mas, sobretudo, tensioná-la em função autoavaliativa e prospectiva.

\title{
Pedagogia e gestão educacional: uma relação de longa data e diversos questionamentos.
}

\author{
Tenho apenas duas mãos \\ e o sentimento do mundo, \\ porém estou cheio de escravos... \\ Carlos Drummond de Andrade.
}

Já na década de 1930, em meio às tentativas de organização do sistema educacional brasileiro, surgiram demandas para a formação dos gestores escolares. Com essa finalidade, os Institutos de Educação tinham a função de oferecer cursos de Administração Escolar posteriores ao Ensino Médio, com duração de dois anos para quem fosse egresso da Escola Normal e possuísse experiência de três anos na docência (CALIXTO, 2010). Concomitantemente, em 1931, foi proposta a criação da Faculdade de Educação, Ciências e Letras pelo Estatuto das Universidades Brasileiras (CRUZ, 2011). Porém, foi apenas em 1939 que o curso de Pedagogia se generalizou para todo o país através da criação da Faculdade Nacional de Filosofia da Universidade do Brasil (CALIXTO, 2010), definindo [...] um currículo que formaria o bacharel em pedagogia entendido como o técnico em educação que, ao cursar didática geral e especial, se licenciaria como professor (SAVIANI, 2008, 41), 
repetindo a organização de " $3+1$ " das outras licenciaturas, que trouxe diversos problemas para a formação e o exercício profissional dos pedagogos.

As dificuldades postas a partir dessa organização provocaram tentativas de resolução dado que, por exemplo, nas escolas, a formação específica em Administração Escolar era exigida apenas para diretores de escolas elementares, que deveria ser realizada em cursos de nível pós-normal [...]. Para os diretores das escolas de nível médio não era exigida formação especifica (WERLE, 1992, p. 69). Assim, procurando garantir emprego aos pedagogos egressos, em 1943, passou a ser exigido o diploma de bacharel em Pedagogia para o preenchimento de cargos de técnicos em educação do Ministério da Educação (MATHEUSSI; FILIPAK, 2008).

A partir de 1962, as disciplinas de licenciatura, dentre as quais contava Elementos de Administração Escolar - sete anos depois substituída por Estrutura e Funcionamento do Ensino de $2^{\circ}$ Grau (WERLE, 1992) - poderiam ser cursadas concomitantemente com o bacharelado, mantido o caráter generalista e, por esse motivo, não podendo se comprometer com atribuições, responsabilidades ou tarefas restritas a funções específicas ou determinado nível de ensino (Ibidem, p. 70), ou seja, ainda permitindo a atuação do pedagogo bacharel apenas na administração central.

Entretanto, o entendimento dessa formação mudou a partir da Reforma Universitária de 1968. Naquele momento, a compreensão foi de que o curso de Pedagogia poderia contar com uma base comum e outra, diversificada. Assim,

O aspecto mais característico da referida regulamentação foi a introdução das habilitações visando a formar "especialistas" nas quatro modalidades indicadas (Orientação Educacional, Administração Escolar, Supervisão Escolar e Inspeção Escolar), além do professor para o ensino normal. As habilitações visavam à formação de técnicos com funções supostamente bem especificadas no âmbito das escolas e sistemas de ensino que configurariam um mercado de trabalho também supostamente já bem constituído, demandando profissionais com uma formação específica que seria suprida pelo Curso de Pedagogia, então reestruturado exatamente para atender a essa demanda. Entretanto, a dupla suposição se revelou inconsistente. Nem as funções correspondentes aos mencionados "especialistas" estavam bem caracterizadas, nem se poderia supor constituído um mercado de trabalho demandando aqueles profissionais correspondentes às habilitações propostas. (SAVIANI, 2007, p. 120).

Perante essas constatações e visando enfatizar a figura do pedagogo como educador, no sentido amplo e abrangente, assim como buscando superar a visão tecnicista e 
burocratizada que afirmava a divisão do trabalho escolar com que tinham se implementado essas habilitações, a reabertura democrática trouxe também um movimento de discussão da formação deste profissional. Ao mesmo tempo, como consequência dessa discussão, houve uma diminuição da contratação de pedagogos para o atendimento pedagógico-didático às escolas por parte das Secretarias de Educação, descaracterizando-os como profissionais. Com isso, as associações nacionais de Orientadores Educacionais e de Supervisores Educacionais, por exemplo, se autodissolveram, resultando na perda do espaço de discussão teórico-prática da pedagogia e do exercício profissional do pedagogo existente nessas associações (LIBÂNEO; PIMENTA, 1999, p. 246).

Anos depois, a Lei de Diretrizes e Bases da Educação Nacional nº 9394/96 (LDB/96), no seu artigo 64, definiu que a formação de profissionais da educação [...] para administração, planejamento, inspeção, supervisão e orientação educacional para a educação básica, será feita em cursos de graduação em Pedagogia ou em nível de pósgraduação. Entretanto, as orientações para essa formação só se consolidaram em 2006, por motivo da implementação das Diretrizes Curriculares do curso de Pedagogia, elaboradas pelo Conselho Nacional de Educação. Essas diretrizes fixaram a identificação da Pedagogia com a função docente, afirmação que não se encontra livre de questionamentos, entre os quais

A insuficiência mais evidente refere-se à falta de uma conceituação epistemológica clara de Pedagogia. O texto estabelece a que se destina o curso, as modalidades de formação, as competências do egresso, mas não explicita a natureza e o objeto do campo do conhecimento pedagógico. Sem definir previamente o que é a Pedagogia, introduz no artigo $2^{\circ}$ a conceituação de docência nos seguintes termos: "Compreende-se docência como ação educativa e processo pedagógico metódico e intencional, construído (sic) em relações sociais, étnico-raciais e produtivas, as quais influenciam conceitos e objetivos da Pedagogia" (Brasil, 2005). Surgem daí perguntas embaraçosas. As referidas diretrizes não são para o curso de Pedagogia? Por que o campo a ser conceituado é o da docência? Pedagogo e professor são conceitos sinônimos? As funções desempenhadas pelo professor são as mesmas destinadas ao pedagogo? Historicamente, pedagogo e professor foram profissões idênticas? Formar alguém para ser professor requer as mesmas capacitações, as mesmas condições curriculares, que formar um pedagogo? Todo professor é pedagogo? Todo pedagogo é professor? [...] em todo o texto da resolução, a única definição teórica de termos, é a mencionada conceituação de docência. Observe-se contudo que essa definição é insustentável do ponto de vista lógico, pois define o termo principal pelo secundário, ou seja, a docência, um conceito subordinado à Pedagogia, é identificado com sendo a própria Pedagogia. (FRANCO; LIBÂNEO; PIMENTA, 2007, p. 91). 
Instaurou-se a figura do pedagogo-docente, não sem tensas discussões e resistências, inclusive, dos próprios conselheiros, dois dos quais declararam seu voto chamando a atenção sobre a restritividade de tornar o curso uma licenciatura preponderantemente voltada à formação docente sem abranger de forma mais ampla os componentes acadêmicos e legais da formação de Pedagogos, como afirmaram os conselheiros Paulo Barone e César Callegari, no Parecer CNE/CP No: 5/2005. Isto, mesmo contemplando que a LDB reconhece que $a$ experiência docente é pré-requisito para o exercício profissional de quaisquer outras funções de magistério, nos termos das normas de cada sistema de ensino.

No meio dessas discussões, segundo esse Parecer, o perfil do Licenciado em Pedagogia deverá contemplar:

[...] consistente formação teórica, diversidade de conhecimentos e de práticas, que se articulam ao longo do curso. Assim sendo, o campo de atuação do licenciado em Pedagogia deve ser composto pelas seguintes dimensões:

- docência na Educação Infantil, nos anos iniciais do Ensino Fundamental, nas disciplinas pedagógicas do curso de Ensino Médio na modalidade Normal, assim como em Educação Profissional, na área de serviços e apoio escolar, além de em outras áreas nas quais conhecimentos pedagógicos sejam previstos;

- gestão educacional, entendida numa perspectiva democrática, que integre as diversas atuações e funções do trabalho pedagógico e de processos educativos escolares e não escolares, especialmente no que se refere ao planejamento, à administração, à coordenação, ao acompanhamento, à avaliação de planos e de projetos pedagógicos, bem como análise, formulação, implementação, acompanhamento e avaliação de políticas públicas e institucionais na área de educação;

- produção e difusão do conhecimento científico e tecnológico do campo educacional. (Parecer CNE/CP N ${ }^{\circ}$ :5/2005, p. 8).

A partir dessas orientações foram sendo modificados os projetos pedagógicos e currículos dos cursos de Pedagogia, enfatizando a figura do pedagogo-docente com um perfil generalista, ou seja, sem habilitações específicas como outrora. Ao mesmo tempo, o sistema educacional brasileiro passou por profundas mudanças no que se refere à sua administração, trazendo complexas e novas demandas para a gestão escolar. Com efeito, por um lado, muitas vezes contradizendo o que se encontra instituído nas rotinas escolares, a implementação da gestão democrática demanda dos gestores conhecimentos e habilidades específicas sobre planejamento escolar participativo para a elaboração do projeto político-pedagógico, do plano de ação, entre outros; processos de coordenação que visem à unidade das ações pedagógicas considerando as diversidades existentes na escola atual, assegurando os diferentes processos 
de inclusão de todos os sujeitos participantes e a garantia do direito à educação e, portanto, à aprendizagem; estabelecimento da democracia deliberativa nos diversos âmbitos escolares, como podem (e devem) ser os conselhos escolares, envolvendo toda a comunidade escolar, entre outros.

Por outro lado, a partir da introdução de dispositivos da administração gerencial na administração pública (PAES DE PAULA, 2005), a educação básica passa a ser vista como um serviço que deve prezar pela satisfação do cidadão enquanto consumidor, entendendo a sua gestão como corresponsável pelos resultados educacionais com organizações mais flexíveis, de administração descentralizada, autônoma e participativa (CARVALHO, 2009, p. 1146). Neste caso, a concepção de participação da sociedade adotada pelo modelo gerencial é pautada na ideia de controle social, como mecanismo de acompanhamento das ações estatais e supõe, como parte das suas estratégias de regulação, diversos dispositivos de avaliação de resultados que reconfiguram determinados papéis no sistema educativo (Ibidem).

Assim, além da ampliação de projetos, parcerias e recursos que passam a ser administrados diretamente pela escola e que demandam habilidades específicas de negociação, planejamento e rendição de contas dos gestores escolares ${ }^{\mathrm{ii}}$, a demanda pela avaliação institucional vem se instituindo com firmeza através do Sistema de Avaliação da Educação Básica (SAEB) ${ }^{\mathrm{iii}}$. Além disso, com base na Prova Brasil e nos dados do Censo Escolar, elabora-se o principal indicador de resultados educacionais do Brasil, o Índice de Desenvolvimento da Educação Brasileira (IDEB). Supõe-se, entretanto, que cabe aos gestores escolares efetivar o processo de referencialização (FIGARI, 1999) destes indicadores em cada escola junto à equipe docente, ou seja, de interpretação e qualificação desses indicadores através dos processos da autoavaliação institucional em função do planejamento escolar, visando à melhoria da qualidade da educação oferecida - que em alguns sistemas, a partir de políticas de responsabilização "forte" (high stake), se atrela a peculiares consequências para a equipe escolar em caso de atingir ou não as metas estipuladas.

Desta forma, entre a tradição burocrática e as atuais demandas de uma gestão tanto societal quanto gerencial (PAES DE PAULA, 2005), as diversas funções da gestão escolar vêm assumindo uma complexidade crescente. Por isso, evidenciam-se diversas iniciativas de formação dos gestores da educação nas esferas Municipais, Estaduais e Federal ${ }^{\mathrm{iv}}$, assim como a preocupação central na Meta 19 do Plano Nacional de Educação 2014-2024, em resolver dois grandes problemas da gestão escolar brasileira atual: a escassa formação específica dos 
gestores e a indicação política como forma preponderante de provimento do cargo de direção. Este plano estabelece, na sua Meta 19, a necessidade de

assegurar condições, no prazo de dois anos, para a efetivação da gestão democrática da educação, associada a critérios técnicos de mérito e desempenho e à consulta pública à comunidade escolar, no âmbito das escolas públicas, prevendo recursos e apoio técnico da União para tanto.

Embora as estratégias associadas a essa meta contemplem todos os aspectos da gestão democrática escolar, chama a atenção a associação da efetivação da gestão democrática a "critérios técnicos de mérito e desempenho" que, decerto, gerará longos debates e diversas interpretações, dado que, já na Estratégia 19.1, essa associação fica vinculada, especificamente, à forma de provimento do cargo de direção que deverá considerar [...] conjuntamente, para a nomeação dos diretores e diretoras de escola, critérios técnicos de mérito e desempenho, bem como a participação da comunidade escolar. A "fórmula" a implementar supõe a combinação de critérios tanto técnicos, que não se encontram bem definidos, podendo abranger tanto questões formativas quanto de algum outro tipo ainda não muito evidente; quanto políticos, o que buscaria garantir não apenas um perfil profissional idôneo (idoneidade que caberia discutir), mas, também, a liderança política necessária para conduzir e representar uma escola.

De qualquer maneira, no contexto educacional atual, seja para o exercício dos cargos de direção, orientação educacional e coordenação pedagógica, há uma grande exigência de saberes e habilidades específicas que se manifestam cardinais para a gestão escolar no sentido de garantir a democratização da educação. Isto porque, além do seu papel pedagógico junto aos outros docentes da escola, os gestores precisam estar dispostos a assumirem a representação política e a articulação/condução coletiva que o seu lugar organizacional lhes confere e, portanto, demanda. Essa demanda ao estar baseada na participação deliberativa nas discussões públicas exige dos gestores reciprocidade, publicidade e accountability (GUTMANN; THOMPSON, 1996; 2004 apud MARQUES, 2012). A reciprocidade refere-se ao respeito mútuo que os cidadãos devem demonstrar uns pelos outros, resultando numa discordância civilizada; a publicidade diz respeito às razões que são oferecidas pelos participantes para justificar decisões e ações em função do melhor encaminhamento para todos e não apenas buscando favorecer interesses particulares; e, por fim, a responsabilização 
que qualquer representante público deve assumir em relação às suas ações com base nos compromissos públicos assumidos.

Assim mesmo, cabe destacar que o trabalho da gestão educacional excede amplamente o espaço escolar, pois o campo profissional da Pedagogia envolve processos de planejamento, coordenação, avaliação etc. em diferentes organizações não-escolares onde também se desenvolvem projetos educacionais.

Como evidenciado até aqui, ao mesmo tempo em que a formação dos gestores educacionais no curso de Pedagogia foi se subsumindo à proposta de um profissional generalista com foco na docência, as demandas específicas para a sua atuação foram se tornando extremamente desafiadoras, em especial, perante as exigências de responder às funções tanto administrativo-gerenciais quanto sócio-políticas que são de sua incumbência atual. Nesse sentido,

Compreende-se que a formação de especialistas em Educação como ocorria até 2006, possivelmente, limitava o conhecimento da área apenas aqueles que optavam por cursar a habilitação em Administração Escolar. O que se indaga é como as Universidades estruturarão o currículo do curso de Pedagogia? A distribuição de disciplinas será a mesma para as três áreas de conhecimento (pesquisa, docência e gestão), ou alguma área será privilegiada em detrimento de outra? [...] Os documentos legais propõem a formação de um educador apto a participar do processo de gestão da escola e que tenha compromisso político, porém [...] A identidade do administrador escolar parece estar se consolidando em uma formação generalista e desprovida dos conhecimentos específicos da área da Administração Escolar, uma vez que esse profissional (se assim poderá ser designado) passa a ser formado no curso de Pedagogia, sendo a Administração uma das disciplinas a ser abordada ao longo do curso. (CALIXTO, 2010, p. 117-118).

\section{Prática em Política e Administração Educacional: uma proposta de formação inicial.}

O que se consegue ver no cotidiano depende das perguntas que fazemos e da orientação que lhes é dada. (ZACCUR, 2003, p. 193).

Em 2010 trabalhei como professora substituta na UFRJ, ficando responsável pelas disciplinas Educação Brasileira e Prática em Política e Administração Educacional (PPAE). Essa não era a minha primeira incursão na formação de gestores educacionais, dado que já vinha lecionando diversas disciplinas relacionadas à área desde 1997, em princípio, na Universidad Nacional de Entre Ríos, no meu país natal, onde me graduei como bacharel em 
Ciências da Educação com orientação em Planejamento e Administração Educacional. Posteriormente, também participei como docente de diversos cursos de extensão na Universidade Federal Fluminense (UFF), onde também fui professora substituta da área em Angra dos Reis e Niterói, assim como trabalhei nas especializações de duas universidades privadas da cidade do Rio de Janeiro que, através de convênios com as prefeituras, interiorizavam o seu atendimento, possibilitando-me conhecer um pouco mais da realidade fluminense.

O início com a disciplina de PPAE não foi fácil, pois poucas foram as orientações por parte da chefia do Departamento: os estudantes deveriam realizar um estágio de $90 \mathrm{~h}$ junto à gestão escolar ou nas instâncias intermediárias da gestão central dos sistemas educacionais com os quais a UFRJ tem convênio e, havendo cumprido com pelo menos $75 \%$ das $60 \mathrm{~h}$ de aulas presenciais na faculdade, teriam de entregar um relatório dando conta da experiência de estágio e suas reflexões. A elaboração do relatório contabilizaria $30 \mathrm{~h}$ de atividades complementares incluídas na carga horária de cada uma das cinco disciplinas de Prática com Estágio Supervisionado do curso, oferecidas na seguinte sequência: Ensino em Magistério das Disciplinas Pedagógicas do Ensino Médio, Política e Administração Educacional, Ensino em Educação Infantil, Ensino nos Anos Inicias do Ensino Fundamental e Ensino na Educação de Jovens e Adultos.

O motivo desse laconismo talvez se devesse ao fato de que a disciplina só tinha sido oferecida uma vez, dada a progressão da implementação do novo currículo do curso, e a que, apesar de dois sucessivos concursos para professor adjunto para o setor curricular de Gestão e Avaliação dos Sistemas Educacionais, não fora possível aprovar nenhum dos candidatos. Perante essa dificuldade, dois professores de Educação Brasileira assumiram transitoriamente a disciplina com a proposta que me fora explicada naquela ocasião.

Com essas orientações comecei a imaginar como organizar a sequência dos conteúdos a serem trabalhados, a bibliografia e os materiais didáticos, entre outros aspectos. Para isso, fui buscar no Projeto Pedagógico do Curso (PPC) as coordenadas para situar o meu trabalho. No PPC afirma-se uma história institucional, desde os anos de 1990, marcada pela

[...] convicção de que o caminho a ser seguido pelo curso de Pedagogia passava necessariamente pela valorização do magistério, levando a que se estabelecesse a formação do professor como finalidade da graduação em Pedagogia da UFRJ e colocando-se as demais áreas nos 4 âmbitos dos cursos de especialização (lato sensu). Após longo período de debates e sistematização de propostas, aprovou-se um novo currículo para o curso de 
Pedagogia da FE/UFRJ, que entrou em vigor em 1993, procurando atender, em sua origem, às demandas do sistema educacional brasileiro, identificadas à época. Para tanto, suprimiu as habilitações correspondentes à formação de especialistas, manteve a habilitação em Magistério das Disciplinas Pedagógicas do Ensino de $2^{\circ}$ Grau, introduziu uma habilitação em Educação Pré-Escolar e outra em Magistério das Séries Iniciais do $1^{\circ}$ Grau. (PPC, 2007, p. 3-4).

Essa convicção, que continua presente na identidade institucional, manifestou-se de diversas formas com o passar do tempo. Assim, percebeu-se que da cisão entre habilitações para a gestão educacional tinha se passado para uma outra, desta vez, com relação aos diferentes âmbitos de atuação dos pedagogos como docentes nos níveis do sistema educacional, além de restringir as possibilidades de exercício profissional para o egresso. A concepção de Pedagogia tinha se reduzido à formação de professores, evidenciando a ausência de uma habilitação que contemplasse também outros espaços de trabalho específicos dos profissionais da Pedagogia, como a gestão educacional.

A esse debate sobre o currículo do curso somaram-se, em 2006, as questões das Diretrizes Curriculares para o curso de Pedagogia, resultando num processo de reformulação curricular que, aprovado em 2007, implementou-se em 2008. O novo currículo afirma que a formação em Pedagogia supõe que [...] a condição de professor constitui sua identidade básica, à qual se agrega a de profissional preparado para atuar na política e na administração educacionais, conforme propõe a LDB 9.394/1996, artigo 64 (PPC, 2007, p. 10). O currículo se propõe a formar pedagogos para atuarem em cinco áreas concomitantes, que são as oferecidas nas disciplinas de Prática e Estágio Supervisionado já mencionadas, e nos seus objetivos reafirma que:

As atividades docentes também compreendem participação na organização e gestão de sistemas e instituições de ensino, englobando: - planejamento, execução, coordenação, acompanhamento e avaliação de experiências próprias do setor da Educação; - planejamento, execução, coordenação, acompanhamento e avaliação de projetos e experiências educativas nãoescolares; - pesquisa, produção e difusão do conhecimento científicotecnológico do campo educacional, em contextos escolares e não-escolares. Pelo exposto, constitui objetivo central do curso formar Pedagogos/Docentes capazes de conhecer, analisar e discutir o campo teórico-investigativo da educação, dos processos ensino-aprendizagem e do trabalho pedagógico que se realiza em diferentes âmbitos da sociedade; preparados para intervir nas diversificadas situações apresentadas pela realidade educacional brasileira, capazes de pensar, decidir, planejar, acompanhar, realizar e avaliar atividades educacionais em várias instâncias e níveis e de produzir conhecimento investigativo sobre a área. (PPC, 2007, p. 12). 
O desenho curricular contempla três núcleos estruturantes: I- Núcleo de estudos básicos, II- Núcleo de aprofundamento e diversificação de estudos e III- Núcleo de estudos integradores, além do Estágio Curricular Supervisionado nas cinco ênfases formativas do curso, expressas através das disciplinas de Prática. Dentre eles,

O Núcleo de estudos básicos objetiva promover um estudo acurado e reflexivo do campo da educação, apoiado em uma sólida formação teórica dos saberes que fazem interlocução com esse campo e o constituem. De acordo com o artigo $6^{\circ}$, inciso I, alíneas (a até 1) das Diretrizes Curriculares Nacionais do Curso de Pedagogia, esse núcleo trabalhará:

a) Aplicação de princípios, concepções e critérios oriundos de diferentes áreas do conhecimento, com pertinência ao campo da Pedagogia, que contribuam para o desenvolvimento das pessoas, das organizações e da sociedade.

b) Aplicação de princípios da gestão democrática em espaços educativos escolares e não escolares [...]. (PPC, 2007, p. 28. Grifos meus).

Neste desenho do Núcleo de estudos básicos é possível observar que todas as Práticas de Ensino possuem previamente o oferecimento de matérias que promovem a introdução aos temas e conceitos fundamentais das disciplinas e que podem colaborar na problematização do cotidiano escolar vivenciado nos estágios supervisionados. Entretanto, não há disciplinas que ofereçam os subsídios necessários para uma análise mesoinstitucional de organizações sociais como a escola. Isto porque tanto as diversas disciplinas relativas à Sociologia quanto à História da Educação, assim como Educação Brasileira, da forma em que são oferecidas neste curso, tendem a uma abordagem macroinstitucional, ao tempo que as outras disciplinas inscrevem-se nas relações didático-pedagógicas entre os sujeitos de uma forma bastante específica, a exceção de Planejamento do Currículo e do Ensino que pode dialogar com os temas da coordenação pedagógica, apesar desta disciplina estar pensada sem uma discussão prévia sobre Projeto Político-Pedagógico (PPP). Concordo em que todas essas abordagens são imprescindíveis para compreender o ato educativo (escolar), mas para um debate que possa problematizar o nível mesoinstitucional, próprio da gestão educacional, as considero insuficientes.

Igualmente, não há nenhuma disciplina obrigatória que introduza a discussão sobre educação em ambientes não escolares e suas especificidades. O currículo conta com duas disciplinas eletivas: Projetos Pedagógicos, com foco nos movimentos sociais e suas propostas educacionais, e Pedagogia Empresarial, que não são oferecidas de forma continuada por falta 
de carga horária disponível dos docentes do Departamento de Administração Educacional, o menor entre os três departamentos da faculdade.

Por isso, o processo de imersão do estudante no campo escolar específico através do estágio supervisionado de PPAE acontece sem qualquer discussão prévia da abordagem disciplinar própria, como as distinções entre instituição e organização, as especificidades da administração escolar e os debates sobre a assimilação da administração empresarial e militar à gestão escolar, a questão da gestão democrática e da democracia representativo-deliberativa na organização escolar, as relações entre a escola, a cidade e as outras organizações educacionais, entre outras questões.

A ausência da discussão desses conceitos e problematizações na ementa da disciplina, também chamou a minha atenção, pois seu foco não sugere esse aprofundamento:

Ementa: Propostas pedagógicas e estratégias de gestão da escola. Aspectos socioculturais do educando. $\mathrm{O}$ currículo da formação do gestor em Educação. Trajetória escolar: aprovação, repetência e evasão. Práticas de gestão: inovações, criatividade e conservadorismo. Condições de trabalho dos gestores. Relação da escola com o sistema e a comunidade.

Essa configuração da proposta curricular me provocou alguns questionamentos: quais os supostos que fundamentaram essa escolha na hora de planejar o currículo? Seria o entendimento de que só com participar no cotidiano organizacional os estudantes se muniriam dos procedimentos específicos para o exercício da gestão escolar em apenas uma disciplina semestral? Esse entendimento não estaria favorecendo uma visão pragmatista ou, inclusive, tecnicista da gestão educacional, como se o campo não tivesse uma discussão disciplinar aprofundada?

Essas questões só se firmaram quando percebi que, além desta Prática, há apenas uma outra disciplina específica, Orientação do Trabalho Pedagógico, que, apesar de ser obrigatória, tem carga horária reduzida (45h). Como resolver, então, o impasse de ter que formar um pedagogo-docente que possa atuar com profissionalismo também nos processos da gestão educacional quase que preponderantemente em apenas um estágio supervisionado sem discussões específicas prévias e uma disciplina semestral de horário reduzido?

Buscando uma melhor fundamentação da proposta, procedi a uma busca bibliográfica sobre a formação do gestor educacional, mas, não encontrei muitos trabalhos que abordassem o assunto e, menos ainda, que discorressem sobre experiências de formação inicial do gestor em estágios supervisionados nos cursos de Pedagogia conforme a proposta das diretrizes 
nacionais atuais. Calixto (2010) ratifica essa situação ao afirmar a dificuldade de encontrar material sistematizado sobre a formação do administrador escolar com que nos deparamos hoje no país.

Naquele momento, ingressou ao Departamento uma colega que, apesar de ter feito concurso para Educação Brasileira, foi indicada para lecionar a PPAE. E encontrando-nos as duas perante tamanho desafio compusemos uma equipe de trabalho que persistiu por alguns semestres, até o momento em que ela decidiu assumir exclusivamente as disciplinas para as quais tinha concursado. Cabe destacar que no início de 2011, após concurso, tomei posse como professora efetiva da vaga que estava ocupando como professora substituta.

O certo é que, ainda em 2010, implementamos a disciplina conforme o esquema que nos fora repassado, sem grandes determinações de antemão, mas com o afã de experimentar a proposta e, juntas, nos apoiarmos mutuamente no andamento das aulas. A parceria com a colega foi de grande importância para ambas e permitiu poder convidar gestores das redes de ensino, entre outros eventos e ações coletivas, que potencializaram as discussões.

Os estudantes se espalharam por diversas escolas municipais e estaduais, sem restrições, dado que sequer teríamos como indicar alguma escola com a qual nós tivéssemos qualquer tipo de parceria ou aproximação prévia. Essa capilaridade trouxe vantagens e desvantagens para os processos de estágio e sua discussão em sala de aula.

Por um lado, nos permitiu conhecer escolas dispostas a acompanhar os estudantes e a compartilhar com eles não só os seus saberes e preocupações, mas também de solicitar do estudante um envolvimento participativo consistente. Com algumas dessas escolas procuramos um contato mais próximo através de visitas, mas não conseguimos ultrapassar o limite da devolução das "impressões” do estágio e da negociação de número de vagas para o semestre próximo.

Por outro lado, também nos trouxe situações de abuso de poder ou descaso por parte da gestão escolar, especialmente de diretoras que chegaram até o maltrato verbal dos estudantes ou à "utilização" deles apenas em funções repetitivas (cuidar da portaria, atender telefone...), confinando-os num lugar/função específico sem lhes possibilitar a exploração do cotidiano da gestão escolar integralmente. Também tivemos o contrário: diretoras que deixavam os estagiários "soltos", perambulando pela escola sem saber o que fazer. Em um dos casos, uma estudante, após crise de choro em sala de aula, explicou que a diretora a deixara havia dias arrumando o arquivo morto da escola, o que vinha lhe provocando alergias fortes. Um dia, sabendo que iria acontecer um conselho de classe, ela se apresentou na sala 
onde estava por começar a reunião, mas quando a diretora a viu começou a gritar: "O que essa está fazendo aqui!?”. Também se deram casos em que a direção, após vários dias em que os estudantes prestavam esse tipo de "serviços", se negava a assinar as horas de estágio do documento correspondente sem dar explicações.

A partir dessas infelizes experiências, iniciávamos com os estudantes um processo de discussão específica que, por mais que possibilitasse uma compreensão crítica do cotidiano escolar e dos conceitos subjacentes a essas ações, não conseguia amenizar a dor da humilhação ou o medo com relação à autoridade (no caso anterior, propus por diversas vezes uma conversa da minha parte com a diretora, mas a estudante se negou enfaticamente). Ao longo destes primeiros semestres, inclusive, alguns estudantes tiveram de mudar de escola no meio do estágio, situação que não vem mais se repetindo a partir da implementação dos roteiros de observação, que explicarei mais à frente.

Ao mesmo tempo, fomos configurando um conjunto de escolas "indicáveis" que, a cada início de semestre, sugeríamos aos alunos, sem impedi-los de realizar o estágio em qualquer outra escola da sua escolha, contudo, "advertidos" de que situações similares às narradas acima poderiam acontecer, dado que adentrar na gestão escolar implica envolver-se nas tramas do poder institucional.

A realização do estágio junto a gestores educacionais experientes dispostos a dialogar com os estudantes é de fundamental importância no processo de formação inicial. Isto porque para além do conhecimento para a prática, na formação docente, torna-se indispensável um diálogo com o conhecimento na/em prática, na perspectiva do conhecimento em ação, pois

presume-se que estes [os professores] aprendem quando têm a oportunidade de examinar e refletir sobre o conhecimento implícito numa boa prática nas ações contínuas de professores experientes enquanto escolhem estratégias, organizam rotinas de sala de aula, tomam decisões, criam problemas, estruturam situações e reconsideram o próprio raciocínio. Para ampliar, explicitar e articular o conhecimento tácito presente na experiência e na ação consciente dos profissionais mais competentes. (COCHRANSMITH; LYTLE, 1999, p. 19 apud OLIVEIRA, 2015)

Mas como/onde encontrar "boas práticas" de gestão escolar no contexto atual, com equipes de gestão desfalcadas, com muitos orientadores educacionais e coordenadores pedagógicos sem formação específica alguma - com o que muitos deles se "prendem" apenas ao que a legislação diz ser a sua função ou ao que a direção lhes exige, já que foi ela quem a/o “indicou" para a função -, com tempos institucionais para o planejamento e a formação 
continuada em serviço diminuídos, com escassos conselhos escolares funcionando participativamente, entre outras constatações? Isso quer dizer que, simplesmente, devemos “aceitar" essa realidade escolar porque não há outra? Podemos responder essa questão entendendo que

O reconhecimento da manifestação das propriedades sistêmicas e dos constrangimentos estruturais na acção quotidiana é fundamental. Porém, esse reconhecimento não pode fazer a economia do poder constitutivo e criativo da (inter)acção nas realidades escolares. A acção não é nunca uma mera duplicação daquelas propriedades e daqueles constrangimentos. [...] É porque a acção e estrutura são co-constitutivas da realidade que a superação do dualismo e a opção por uma perspectiva que focalize a realidade a partir desta intercepção se tornem fundamentais. A acção estruturante e estruturada (Giddens, 1982) é aquela que quotidianamente faz com que em cada escola se jogue a reinvenção do mundo, por tantas crianças e tantos professores e professoras, em condições que, sendo únicas, têm propriedades que se repetem em cada escola, em cada país e à escala global. (SARMENTO, 2003, p. 94).

A “aceitação" desses cotidianos complexos, intensos e densos, em lugar da procura exclusivamente de "boas práticas" permite movimentos que podem colaborar na consolidação de outras perspectivas de possibilidades. Isto porque a opção por "aceitar" esses cotidianos “ambíguos" - escolha questionada por alguns colegas responsáveis por outros estágios supervisionados -, entretanto, pode possibilitar um conhecimento da prática, com discussões provenientes da experiência no cotidiano escolar, portanto, inseparáveis dos próprios sujeitos, já que

Desta perspectiva, o conhecimento não está amarrado pelo imperativo instrumental que o obriga a ser aplicado em uma situação imediata; pode também moldar os enfoques conceituais e interpretativos que os professores usam para fazer julgamentos, teorizar sobre a prática e conectar seus esforços a questões políticas, intelectuais e sociais mais amplas, bem como ao trabalho de outros pesquisadores, professores e comunidades. (COCHRAN-SMITH; LYTLE, 1999: 16 apud OLIVEIRA, 2015, p. 34).

Esse é o motivo pelo qual, ainda hoje, sugiro algumas escolas que garantem o acolhimento e a orientação dos estudantes - algumas já com parcerias de longa data, com as quais temos realizado outro tipo de ações, inclusive, extensionistas -, mas permito a livre escolha do local de estágio, desde que tenha convênio com a universidade. Essa possibilidade tem promovido um movimento interessante por parte dos estudantes, dado que vários têm optado por estagiar nas escolas onde estudaram, onde seus filhos estudam ou onde trabalham 
em outras funções, permitindo um outro olhar que não raramente os surpreende bastante. Também tenho tido casos em que alguns estudantes, apesar de já terem cumprido as horas de estágio obrigatórias, continuam comparecendo à escola para colaborar com a gestão, dado o grau de envolvimento e compromisso ao que chegaram. Em outros casos, se a professora de Prática de Ensino permitir, preferem realizar o estágio na mesma escola, o que, no meu entendimento, representa uma situação altamente desejável do ponto de vista formativo, já que permite que o estágio docente em sala de aula seja previamente dimensionado no seu contexto organizacional mais amplo, situando a ação específica na ação coletiva.

Todavia, foram surgindo outros problemas, como a demanda dos estudantes a respeito da ausência formativa com relação aos espaços educacionais não escolares. Em função disto, em dois semestres, propusemos que as $30 \mathrm{~h}$ de atividades complementares fossem cumpridas através da realização de estágio nos setores educativos de museus, ONGs com projetos educativos etc. Entretanto, apesar da experiência ter sido relevante, essa opção revelou-se muito complicada porque nem sempre conseguíamos garantir vagas para todos os discentes em tempo, dado que possuíamos poucas organizações conveniadas, motivo pelo qual organizamos um "rodízio" difícil de operacionalizar em apenas um semestre e com o estágio escolar acontecendo concomitantemente. Aliás, a realização dos procedimentos administrativos referentes ao estágio demanda a assinatura de diversos documentos em instâncias que, pelo menos no caso do estágio nas escolas municipais, tem apresentado um enorme grau de detalhismo e, às vezes, aleatoriedade, dependendo do funcionário que atende no momento, obrigando ao estudante a tirar mais fotocopias do mesmo documento e se deslocar até a administração central várias vezes - o que representa gastos consideráveis para os estudantes. Com o acréscimo do estágio não escolar estávamos duplicando esse processo... Um outro problema referia-se à realização de relatórios para os dois estágios, o que para muitos estudantes significou não conseguir entregá-los no final do semestre.

Por esses motivos, cientes da importância da inclusão dessas organizações nas experiências e discussões da disciplina, as $30 \mathrm{~h}$ de atividades complementares passaram a ser organizadas em "aulas de campo", preferencialmente aos sábados, devido aos compromissos de horários dos estudantes com as outras disciplinas e seus empregos. Assim, ao longo do semestre, são oferecidas diversas opções coletivas ou individuais em diferentes bairros da cidade às quais os estudantes podem comparecer. Dessas opções, o aluno deverá realizar obrigatoriamente três e apresentar relatório, procurando uma problematização a partir dos conceitos trabalhados na primeira unidade do curso: direito à cidade, cidade educadora, 
educação em museus e sua relação com a escola. Alguns estudantes, porém, mesmo tendo concluído a disciplina, continuam frequentando as atividades.

Todavia, o que mais tem "marcado" a disciplina PPAE tem sido a implementação de roteiros de observação.

Com efeito, os primeiros dois semestres solicitávamos aos estudantes um relatório que desse conta da contextualização da escola, assim como dos processos e procedimentos relativos à gestão escolar vivenciados no cotidiano escolar. Porém, pouquíssimos se revelaram satisfatórios, evidenciando pouca problematização e diálogo com os textos, assim como despercebimento de situações, rotinas e acontecimentos altamente significativos para a gestão escolar. Ao mesmo tempo, a maior parte dos estudantes identificava a direção como sendo "toda" a gestão escolar, conceito contraposto ao princípio da gestão democrática. Essa visão faz com que, em muitos casos, o estudante tenda a se identificar preferencialmente com a perspectiva da direção, sem considerar os diferentes pontos de vista dos sujeitos que participam da escola, convalidando uma espécie de "visão/versão oficial” da escola.

Essa última questão é altamente relevante dado que evidencia, no processo de formação na gestão escolar, os cruzamentos de sentidos e com os poderes institucionais, pois

Uma acção dotada de sentido (e toda a acção social - segundo o sociólogo alemão que melhor a teorizou, Max Weber - só o é na medida em que é uma acção com sentido e, acrescentarei agora, consentida) é também uma acção onde se verifica a luta pela afirmação de sentidos próprios e onde se joga a capacidade dos actores para exercerem o poder de nomeação e, nessa sequência, constituírem as pautas de significação e de conduta [...] Deste modo, para a mesma acção há vários sentidos, e há luta pelo sentido aceite e socialmente confirmado. (SARMENTO, 2003, p. 94-95).

Como promover, então, no processo formativo dos estudantes a superação de perspectivas unilaterais, do reducionismo de sentidos e dos sentidos, aguçando a percepção, o estranhamento e a desnaturalização do cotidiano escolar; o encontro com as diversas dimensões da gestão escolar e da complexidade educacional; a problematização e a análise crítica, convocando a reflexão contemporânea sobre os modos de exercício das relações sociais em sistemas de acção, cuja natureza reside em serem artificiais e relativamente estruturados e duráveis, com a conceptualização das finalidades, das formas e da natureza das relações pedagógicas (Ibidem, p. 95)?

A solução encontrada veio por ocasião de um material impresso ocasionalmente achado que, através de perguntas, tentava promover um exercício de autoavaliação coletiva a 
respeito da gestão democrática na escola. Esse procedimento, bastante implementado nos processo de autoavaliação institucional (processo que faz parte do conteúdo da disciplina PPAE, embora pouco se realize na escola pública brasileira atual) nos inspirou a iniciar o que denominamos de "roteiros de observação", que foram sendo (re)construídos a várias mãos. No início, junto com a professora L., organizamos uma primeira série de perguntas em diálogo com os textos sobre as quais os estudantes teriam de procurar informações ao longo do estágio e, posteriormente, através de um relatório, apresentá-las narrativamente em diálogo com os textos e discussões trabalhados em sala.

Essa orientação de ter o que procurar durante as horas de estágio veio resolver as situações em que a gestão restringia a vivência dos estudantes na escola, dado que o estagiário teria de poder circular pela escola na busca de indícios e informações, inclusive, entrevistando outros sujeitos. Com o tempo, algumas alunas chegaram a sugerir modificações nos roteiros, propondo perguntas a partir dos textos estudados, como aconteceu com a estudante Úrsula G. Dantas de Menezes com o roteiro específico de orientação educacional, e, inclusive, criar roteiros novos, como o escrito pela monitora Amanda dos Santos Pereira, ao considerar que estava faltando um roteiro de observação para as aulas de campo. Amanda iniciou o roteiro com a seguinte epígrafe:

\section{Palavras para uma cidade}

[...] O que sabemos dos lugares é coincidirmos com eles durante um certo tempo no espaço que são. O lugar estava ali, a pessoa apareceu, depois a pessoa partiu, o lugar continuou, o lugar tinha feito a pessoa, a pessoa havia transformado o lugar (José Saramago).

No meu entendimento, elas tinham compreendido o sentido didático-pedagógico desses roteiros: aprender a focalizar a percepção no meio às "turbulências" do cotidiano da gestão escolar, iniciar um processo de pesquisa através da busca de indícios e de conversas, provocando o estranhamento do cotidiano, inclusive tendo que procurar aquilo do qual não se conhecia a existência (como quando ouço: "professora, eu nem sabia que isso existia na escola!"), quando o supostamente banal passa a ter um destaque inusitado ("nunca pensei que o portão da escola fosse tão importante") ou quando as falas dos sujeitos se contrapõem (“afinal, tenho três versões sobre como surgiu a escola, e agora professora? Qual é a verdadeira?") e uma reflexão que, apesar da brevidade da disciplina, possa garantir a abrangência das dimensões da gestão escolar e os necessários aprofundamentos conceituais. 
Ao todo são seis roteiros de observação, que acompanham as unidades de conteúdo, organizados numa sequência que busca facilitar a compreensão da escola no contexto urbano e sócio-comunitário, assim como no sistema educacional para depois aprofundar nas particularidades organizacionais e da gestão escolar. Essa sequência procura acompanhar o movimento de inserção de estágio dos estudantes, assim como "romper" com a visão da escola como "isolada" e possível de compreensão apenas considerando as dinâmicas "intramuros". Desta forma, a Unidade 1: "Educação na cidade" aborda as seguintes temáticas:

Cidades educadoras. Escolas e outras instituições educadoras no espaço urbano. Gestão educacional em museus, centros culturais, ONGs e empresas: espaços, tempos e projetos político-pedagógicos. A materialidade da gestão educacional: infraestrutura, dimensões funcional, relacional e temporal dos espaços institucionais e urbano. $\mathrm{O}$ poder na cidade: espaço urbano, violência e educação.

As leituras e debates desta unidade promovem uma visão mais ampla sobre o direito à cidade e os diferentes espaços educacionais para além da escola, servindo de base para a elaboração dos roteiros das aulas de campo, ao mesmo tempo em que oferecem referências conceituais para problematizar os dados levantados no primeiro roteiro de observação, denominado "Materialidade da escola". Neste roteiro, cujo relatório - que deve conter mapas, plantas e fotos - deve ser entregue 15 dias após o ingresso à escola, as perguntas abordam:

- a localização da escola na rede escolar e no espaço urbano (localização nos mapas com escalas diferentes, localização de outras organizações que educam, assim como de outras escolas públicas e privadas e de organizações que representem a presença do estado no bairro, levantamento da topografia e de riscos possíveis etc., dados demográficos e de matrícula); - as características de atendimento da escola (fluxo e mobilidade da matrícula, proveniência dos estudantes, formas de acesso à escola etc.); - os aspectos construtivos, dimensionais e de uso dos prédios escolares (arquitetura escolar tanto nos seus aspectos materiais e físicos iluminação, ventilação, manutenção etc. - quanto simbólicos - comunicação visual, estética, pedagógica etc. -, materiais didáticos e espaços pedagógicos - biblioteca, parquinho, laboratório etc. -, acessibilidade e sustentabilidade); - as dimensões funcionais, relacionais e temporais da escola (usos e apropriações dos espaços escolares por parte dos diferentes sujeitos, lugares e fluxos, "barreiras" visíveis e invisíveis, riscos e segurança etc.).

A seguir, as discussões sobre a presença/ausência do Estado, poder paralelo e sociabilidade violenta, implantação de Unidades de Polícia Pacificadora, entre outros, servem 
de referências para problematizar os dados levantados no roteiro de observação 2, "Escola, poder e relações sócio-comunitárias", que solicita a realização de entrevistas a sujeitos diversos da escola em função de conhecer o surgimento da escola, as relações da escola com as organizações do bairro, a existência de narcotráfico ou milícias e como isso afeta a escola, relações escola-comunidade e clima institucional.

Uma vez localizado o estudante na escola e no seu contexto, a escola em si passa a ser o foco de reflexão. Assim, a Unidade 2: "Fundamentos da gestão escolar", focaliza nos debates sobre: "Escola e paradigmas de gestão. A especificidade da gestão escolar. Gestão democrática da educação: contextualização, problemáticas e perspectivas. Formação e funcionamento dos Conselhos Escolares". E a Unidade 3: "Sujeitos, projetos, processos e resultados na gestão educacional" enfatiza os seguintes tópicos: "Projeto político-pedagógico e planejamento participativo: autonomia, poder e conhecimento. A orientação educacional e pedagógica nos processos de gestão. Financiamento da educação. Qualidade social e avaliação da educação".

Ao longo das discussões sobre esses assuntos em sala de aula, os estudantes devem entregar os relatórios faltantes. Assim, o roteiro de observação 3, "Projeto PolíticoPedagógico (PPP) e Gestão Democrática”, envolve questões sobre a autoria, elaboração, formato e implementação do PPP, relação com outros projetos e parcerias público-privadas presentes na escola, existência e funcionamento de conselhos escolares, grêmio estudantil etc., circulação e publicização das informações e participação.

Por sua vez, o roteiro de observação 4, "Orientação Educacional e Pedagógica", procura identificar essas duas funções no cotidiano escolar, dado que há muitas escolas que não possuem esses profissionais específicos. Assim, além das rotinas específicas, procura-se uma reflexão sobre o acompanhamento dos processos de socialização, inclusão e aprendizagem dos estudantes, assim como sobre as articulações promovidas entre os professores, a sua formação inicial e continuada em função do currículo escolar, assim como carreira, avaliação, satisfação e absenteísmo de docentes e funcionários.

Por fim, o roteiro 5, “Avaliação Institucional e Financiamento da Educação", indaga sobre os momentos e ações de autoavaliação institucional, assim como sobre o impacto das avaliações em larga escala e indicadores de qualidade, metas etc. O roteiro solicita também a análise do boletim escolar, identificando taxas de fluxo, distorção idade-série, evasão, níveis de proficiência em Matemática e Português dos estudantes, entre outros dados que aprendem 
a encontrar na internet. Com relação ao financiamento, dados sobre diversas fontes de financiamento da escola, orçamento, rendição e publicização das contas são analisados.

Cabe destacar que todos os roteiros solicitam, no final de cada um deles, que o estudante manifeste o quê mudaria sobre cada aspecto analisado, o que, em alguns casos, após comunicação às equipes gestoras, tem gerado mudanças nos locais de estágio. Durante um tempo, pedi a confecção de slides que sintetizariam as observações levantando os problemas e focalizando nessas sugestões, mas a demora na entrega dos relatórios não tem permitido essa ação de síntese que se revelou importantíssima também para socialização de experiências nas turmas. Em outros casos, percebi a "burocratização" das respostas, ou seja, em lugar de um roteiro de observações que pudessem desencadear uma reflexão, as respostas transformaramse num "check list" sem sentido que, se o estudante entregar a tempo dentro do semestre, solicito refazer respondendo às orientações iniciais, ou seja, trazendo suas vivências, reflexões e problematizações em diálogo com os textos. Por fim, outros, aproveitam a elaboração destes roteiros como capítulos de apresentação e contextualização das escolas focalizadas em suas monografias ou trabalhos de outras disciplinas, sendo também fonte de inquietações para definir seus temas e problemas de pesquisa.

\section{Considerações finais}

O currículo do curso de Pedagogia da UFRJ está passando por um processo de reformulação atualmente. Como representante da área de Gestão e também por ser professora de uma disciplina de Prática com Estágio Supervisionado participo da comissão encarregada desta complexa e desafiadora tarefa. Como garantir a formação de um pedagogo que, como profissional, possa enfrentar satisfatoriamente as complexidades e demandas específicas para a sua atuação como gestor educacional no momento atual, em especial, perante as exigências de responder às funções tanto administrativo-gerenciais quanto sócio-políticas? Isto num contexto em que a Pedagogia foi se subsumindo à proposta de um profissional generalista com foco na docência, com pouco espaço para a formação específica, como vimos também definir este currículo.

Essa responsabilidade e o escasso tempo de que dispomos para isso, se faz sentir nos percursos discentes. Assim, no seminário de avaliação do currículo do curso realizado recentemente, em tom de crítica, os estudantes manifestaram que esses roteiros são 
extremamente "extensos e densos", dificultando a entrega dentro dos prazos estipulados, assim como a sua devolução em tempo. Cabe agora, além de repensarmos o currículo, investigar quais têm sido as contribuições desta proposta didática para aqueles que já se encontram exercendo a profissão de pedagogo. Esse, portanto, é o próximo desafio...

\section{REFERÊNCIAS}

BRASIL. Lei n 9394. Estabelece as Diretrizes e Bases da Educação Nacional. Diário Oficial da União, Brasília. 20 dez. 1996.

BRASIL. Plano Nacional de Educação 2014-2024: Lei no 13.005, de 25 de junho de 2014, que aprova o Plano Nacional de Educação (PNE) e dá outras providências. Brasília: Câmara dos Deputados, Ed. Câmara, 2014.

CALIXTO, E.A. A construção do conhecimento sobre a formação do administrador escolar: uma análise a partir das publicações nacionais. Dissertação de Mestrado, Universidade Estadual Paulista - UNESP, São Paulo, 2010, 133 f. Disponível em: <http://repositorio.unesp.br/handle/11449/96311>. Acesso em: 08 nov. 2015.

CARVALHO, E. J. Reestruturação Produtiva, Reforma Administrativa do Estado e Gestão da Educação. Educação e Sociedade, v.30, n.109, p. 1139-1166, set.-dec. 2009.

COCHRAN-SMITH, M.; LYTLE, S.L. Relationships of Knowledge and Practice: teacher learning in communities. In: Review of Researchs in Education, USA, 24, 1999.

CRUZ, G.B. Curso de Pedagogia no Brasil: história e formação com pedagogos primordiais. Rio de Janeiro: Wak Editora, 2011.

FIGARI, G. Para uma referencialização das práticas de avaliação dos estabelecimentos de ensino. In: Estrela, A.; Nóvoa, A. (Orgs.). Avaliações em Educação: novas perspectivas. Porto Editora: Porto, Portugal. 1999.

FRANCO, M.A.S.; Libâneo, J.C.; Pimenta, S.G. Elementos para a formulação de Diretrizes Curriculares para Cursos de Pedagogia. In: Cadernos de Pesquisa, v. 37, n. 130, jan./abr. 2007.

LIBÂNEO, J.C.; PIMENTA, C.G. Formação de profissionais da educação: visão crítica e perspectiva de mudança. In: Educação \& Sociedade, ano XX, n.68, Dez/1999.

MARQUES, F.P.J.A. O problema da participação política no modelo deliberativo de democracia. In: Revista Sociol. Polit., Curitiba, vol. 20, n 41, p. 21-35, fev. 2012. Disponível em: http://revistas.ufpr.br/rsp/article/view/31768. Acesso em 15/08/2014.

MATHEUSSI, E.M. e FILIPAK, S.T. O curso de Pedagogia no Brasil e sua Normatização. Disponível em: 
<http://www.portalanpedsul.com.br/admin/uploads/2004/Poster/Poster/06_21_33_O_CURSO _DE_PEDAGOGIA_NO_BRASIL_E_A_SUA_NORMATIZACAO.pdf $\geq$. Acesso em 16 jun. 2016.

\section{OLIVEIRA, F.L. Diferenciais do PIBID UFRJ Pedagogia na docência de dois professores da educação básica. Monografia apresentada em 2015. Faculdade de Educação, UFRJ.}

PAULA, A.P. Administração Pública Brasileira entre o Gerencialismo e a Gestão Social. In: Rev. ERA, V. 45, Nº1. 2005. Disponível em:

<http://www.scielo.br/pdf/rae/v45n1/v45n1a05.pdf $\geq$. Acesso em 15 ago. 2014.

SARMENTO, M.J. Quotidianos densos. A pesquisa sociológica dos contextos de acção educativa. In: GARCIA, R.L. (Org.). São Paulo: Cortez, 2003.

SAVIANI, D. Pedagogia: o espaço da educação na universidade. In: Cadernos de Pesquisa, v. 37, n. 130. Jan/abril 2007.

WERLE, F.O.C. Formação do Administrador da Educação no Brasil: uma tentativa de periodização. In: Cad. Pesq. São Paulo, n. 82, agosto/1992.

ZACCUR, E. Por que não uma epistemologia da linguagem? In: GARCIA, R.L. (Org.). Op. cit. 2003.

\footnotetext{
' Professora adjunta da Universidade Federal do Rio de Janeiro, membro do Núcleo Docente Estruturante do curso de Pedagogia, integra a equipe do LaPOpE - Laboratório de Pesquisa em Oportunidades Educacionais

ii Citamos aqui, apenas para exemplificar, o Programa Dinheiro Direto na Escola (PDDE), o Plano de Desenvolvimento da Escola (PDE Escola), assim como as parcerias com ONGs e Fundações diversas, mais conhecidas como Parcerias Público-Privadas.

iii O SAEB inclui a Avaliação Nacional da Educação Básica (ANEB) e a Avaliação Nacional do Rendimento Escolar (ANRESC), mais conhecida como Prova Brasil, e a Avaliação Nacional da Alfabetização (ANA).

iv Por exemplo, o Programa de Capacitação a Distância para Gestores Escolares (PROGESTÃO), desenvolvido pelo Conselho Nacional de Secretários de Educação (CONSED), em parceria com as Secretarias Estaduais e Municipais de Educação, o Programa Nacional Escola de Gestores da Educação Básica Pública, iniciado pelo Instituto Nacional de Estudos e Pesquisas Educacionais Anísio Teixeira (INEP), em 2005, e atualmente desenvolvida pela Secretaria de Educação Básica do MEC, entre outros, sem contar com os inúmeros cursos oferecidos pelas próprias Secretarias de Educação e/ou as universidades.
} 